\title{
ACCEPTANCE AND USABILITY OF MEDICAL INFORMATICS AMONG PHYSICIANS IN BAHRAIN
}

\author{
Mishleen M. Aqleh, Mukhtar S. AL-Hashimi, Allam Hamdan and Anjum Razzaque \\ College of Business and Finance, Ahlia University \\ Manama, Bahrain
}

\begin{abstract}
Purpose: the main objective is to explore the usability of medical mobile applications and to study the factors affecting the acceptance of the Electronic Medical Record Systems (EMRs) among physicians in Bahrain. Methodology: The study followed a quantitative design employing a questionnaire based on the Extended Technology acceptance Model (TAM2) to test the relationship between the acceptance of EMRs and the factors affecting it; System Perceived Usefulness (PU), Perceived Ease of Use (PEOU), Job Relevance and Output Quality in addition to descriptive questions to understand the extent of use of the mobile medical Apps among the physicians. The study covered 53 physicians from various hospitals across Bahrain. SPSS was used to analyze data. Findings: Acceptance of EMR is positively affected by US, EOU, Job Relevance and Output Quality and thus accepts all the intended hypothesis. Implication: the research emphasizes on the role of hospitals' management to introduce the importance, usefulness and impact of such technological advancements on the physicians work flow and quality of patient care and to provide effective training and support on how to use the implemented EMR so end-users may own the system.
\end{abstract}

\section{KEYWORDS}

Medical Information Systems, Electronic Medical Records, Technology Acceptance, Physicians, Mobile Health, Smartphones, Medical Applications, Usability

\section{INTRODUCTION AND BACKGROUND}

Advancements medical practice and introducing Medical Informatics in the diagnosis, treatment and processing of the information has helped the health organizations profoundly improve its functioning. Medical Informatics, in the context, is a huge technological advancement that has interacted with the medical professionals in different domains of work and were described by J C Wyatt and J L Y Liu as "Mechanical computing in medicine" and they defined it as: "the study and application of methods to improve the management of patient data, clinical knowledge, population data, and other information relevant to patient care and community health" (Wyatt \& Liu, 2002). There is a huge variety of applications and software available that range from simple (e.g. transaction processing systems) to complex systems such as clinical decision support systems (CDSS) and used according to the need and interactivity of the health professionals. Likewise, Smartphones have captured the attention of the physicians worldwide as the medical and patient oriented applications available on these devices enable the doctors at the point of care to get the information needed for diagnosing, treating and controlling different patient health conditions and diseases (Okazaki et al., 2015; Wyatt et al., 2013). One of the most supported medical informatics systems is the patient centered type, Electronic Medical Records (EMR) through which the analyses of patients' data helps reaching the best diagnosis of any health problem, whether it was an acute or a chronic disease, faced by the profession, and deciding the most appropriate treatment needed for the patient, in addition to enhancing the quality of service delivery (Marques et al., 2011). EMR is nowadays available and implemented in hospitals, clinics and medical centers in many countries, and Bahrain is one of them, thus understanding the acceptance of EMR by physicians and the factors affecting it is very crucial to make sure that the EMR systems are finely integrated and that the anticipated benefits will be eventually demonstrable (Gagnon et al., 2014). In addition, with the increase reliability of doctors on the medical apps and their ability to carry textbooks and access different data resources (e.g. medical calculator, and medications prescriptions) on their smartphones (Payne et al., 
2012), it's important to study the usability of smartphones in the medical practice and the kinds of apps that are most widely used among doctors in Bahrain. Nowadays, there are more than 10,000 easily accessed health care applications stored in iOS (Apple operating system) serving all areas of medicine such as patient management, educational, research, and referencing.

The health industry in some countries is utilizing these devices and apps for the management of medical data, retrieval the patients' electronic medical records, clinical communication between physicians and patients (such as HealthJump App), trackers eye and skin diagnosis, blood pressure measurement and many more (Gan et al, 2016) (Gan et al., 2016). Using such improvements as EMR, and mobile-health (m-health) and likewise have been extensively recommended for their roles in enhancing the patient care quality in medical area (Moeinedin, 2011) together with the frequent and dramatic changes in the medical domain, which mandates the full acceptance of these systems by physicians and healthcare providers (Pai and Huang, 2011). The term "Acceptance" was defined in most of the literature referring to the original definition that had been constructed by Davis et al., described it as "users' decision about how and when they will use technology" (Davis et al., 1989). Research was conducted in UK in 2015 by R.K Patel et al, , evaluating surgical doctors' utilization of smartphones, medical apps popularity and use of internet activities (Illiger et al., 2014). Through a questionnaire approach to pinpoint the percentage of surgical doctors of all levels utilizing smartphones in their clinical practice (ibid). They assessed the usage of medical applications, and online medical resources, and evaluated if smartphones users were likely to utilize their own smartphone for clinical context. The results indicated that $54.2 \%$ of the doctors downloaded medical applications and $86 \%$ used smartphones for accessing information/online: especially juniors more than the seniors, (ibid) which contradicts with Illiger et al. (2014) who stated that using the tablets does not depend on age. Although most of Bahrain local and private hospitals have implemented the EMR systems and have started using them, there are no studies on the acceptance and usability of these systems among the physicians, and the factors affecting their intention to use them. Additionally, the availability of specialized medical apps on the Smartphones with the increasing usage of such devices makes it important to quantify their usability in the medical practice and the frequency of usage among physicians in Bahrain. The physicians are the ones who take the decision if they would use a new technology implemented in their workplace or not it's very crucial to find out the key factors affecting their decision to use such technology. So, the objectives of this study are to give a brief image about the EMR acceptance and the factors affecting it, in addition to the usability of Smartphones in clinical practice.

\section{RESEARCH METHODOLOGY}

\subsection{Research Model}

Extended Technology Acceptance Model (TAM 2) theoretical model that has been introduced by Venkatesh and Davis in 2000 to scientifically study how such factors affect technology acceptance by physicians was adopted and employed in this research to be able to answer the research questions. Many studies such as have found that TAM 2 also known as (extended TAM) was one of the most useful methodologies and models to describe the intentions of health healthcare professionals to use technologies and can be adequately applied to improve the way they understand technology care (Sezgin \& Özkan, 2014; Chang, 2015). Each variable's indicators were determined referring to literature studies that have been reviewed. 


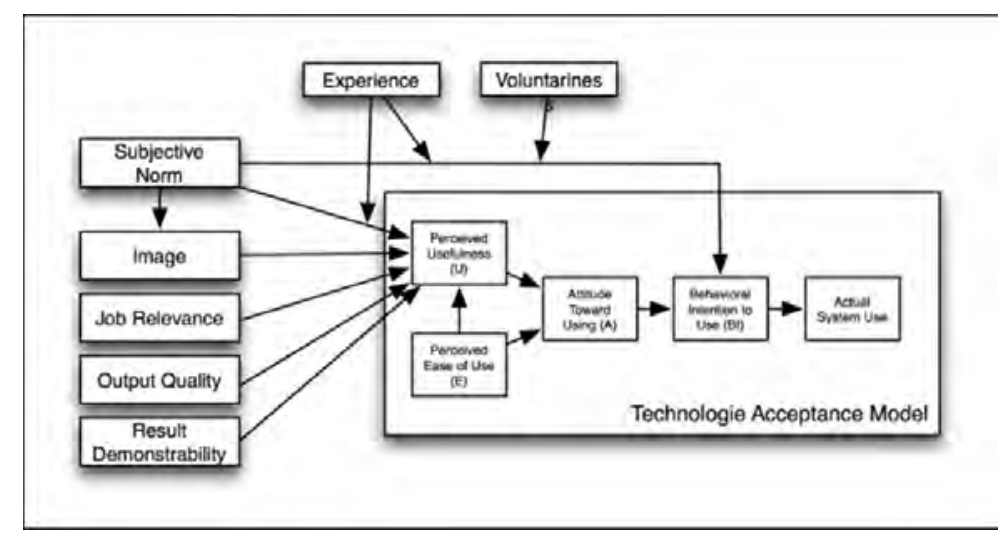

Figure 1. TAM 2

Table 1. TAM2 Constructs

\begin{tabular}{ll}
\hline Construct & Definition \\
\hline Behavioral Intention (BI) & Person's intent to perform activities \\
Attitude & User's positive or negative reaction towards an activity \\
Perceived Usefulness (PU) & User's belief that utilizing a system would enhance his/her performance. \\
Subjective Norm & The perceived social effect on an individual to participate or not in an activity. \\
Image & $\begin{array}{l}\text { The extent to which a person understands the technology use to strengthen his or } \\
\text { her position among people. }\end{array}$ \\
Voluntariness & The degree to which a person decides to adopt and accept technology willingly. \\
Job Relevance & Awareness of how relevant the new technology is to a person's job. \\
Output Quality & The extent to which a system complete tasks related to a person's job. \\
Result Demonstrability & The tangibility of the aftereffects of utilizing the technology. \\
Experience & Knowledge or practical wisdom gained from what one has observed, encountered, \\
& or undergone.
\end{tabular}

\subsection{Research Hypotheses}

For the EMR acceptance, the research hypotheses were adopted from previous literature and studies that were conducted to study the EMR acceptance among doctors and the factors affecting them using the theoretical models of Technology acceptance (Gagnon et al., 2014; Davis et al., 1989). For this study purposes, 4 variables will be hypothesized and discussed. H1: Physicians' "perceived usefulness" of EMR has positive influence on their intention to use the system. H2: Physicians' "perceived ease of use" of EMR has positive influence on their intention to use the system. H3: Job relevance is positively associated with physicians' "perceived usefulness" H4: Quality of output is positively associated with physicians" "perceived usefulness"

\subsection{Research Design}

A quantitative cross- sectional approach using a survey design was chosen to serve the purpose of the study. The questionnaire of 34 questions was adopted from (Payne et al., 2012; Patel et al., 2015; Sweis et al., 2014; Hamidfar et al., 2008): divided in 3 sections; A - participant demographic and job-related details, B measures participant smartphone medical applications usability, and $\mathrm{C}$ measured acceptance of EMRs and factors affecting it. Section C (from 11 to 34) employ "a five-point Likert scale" where 1 being "strongly disagree" and 5 being "strongly agree". Target population was physician using EMRs. Sample selection was thru non-probability convenience sampling technique. The questionnaire was distributed to physicians from different hospitals, clinics and health centers in Bahrain from different specialties and job positions by using the reliable website Survey Monkey® link, and for the limitations that faced the researcher which are mentioned in the introduction chapter, 53 valid fully answered questionnaires were used for the analysis out of only 70 collected. SPSS version 20 software for statistical analysis and data manipulations. Descriptive 
statistics were conducted to show the percentages of the demographical variables and the percentage of the smartphone applications usage among doctors in Bahrain. Moreover, to test the relationship between the dependent variable, intention to use the EMRs, and the independent variables; PEOU and PU, and the interrelationships among variables such as the relationship between the job relevance, and quality of output and PU of the EMR, the researcher employed multiple regression analysis, which is a statistical test used to describe the effect and the relationships between the dependent and the independent variables. F statistics with $\mathrm{P}$ - significance (significance level of 0.01 was chose) besides Beta coefficients and Adjusted R2 values are used to analyze and study the results of regression tests.

\section{RESULT AND DISCUSSION}

\subsection{Respondent's Demography}

Table 2 represents the participants' demographics and percentages. As can be seen, most of the respondents were females $64.2 \%$ and the age range was almost around 30-39-year-old $45 \%$. A percentage of $34 \%$ were of junior doctors and $30.2 \%$ of seniors with $35.8 \%$ from medicine specialty and $22.6 \%$ of Obstetrics and Gynecology. The years of experience of the respondents ranged between less than 1 year and more than 10 years.

Table 2. Demographic Profile of the Participants

\begin{tabular}{llll}
\hline & & Frequency & Valid \% \\
\hline Gender & Male & 19 & 35.8 \\
& Female & 34 & 64.2 \\
\hline age & $20-29$ & 21 & 39.6 \\
& $30-39$ & 24 & 45.3 \\
\hline Seniority level & $40-49$ & 8 & 15.1 \\
& Intern & 2 & 3.8 \\
& Junior & 18 & 34 \\
& Senior & 16 & 30.2 \\
& Chief & 9 & 17 \\
& Consultant & 8 & 15.1 \\
\hline Specialization & GP & 4 & 7.5 \\
& ENT & 1 & 1.9 \\
& Medicine & 19 & 35.8 \\
& Obs \& Gyne & 12 & 22.6 \\
& Pediatrics & 5 & 9.4 \\
& Surgery & 6 & 11.3 \\
& ER & 3 & 5.7 \\
& Nephrocyte & 2 & 3.8 \\
& Family & 1 & 1.9 \\
\hline Work experience & $<1$ year & 15 & 28.3 \\
& $1-3$ years & 8 & 15.1 \\
& $4-6$ years & 11 & 20.8 \\
& $7-10$ years & 9 & 17 \\
& $>10$ years & 10 & 18.9 \\
\hline
\end{tabular}

\subsection{Smartphone Apps Usability}

This section of the analysis is projected at the usability of Smartphones among doctors in Bahrain, showing the important role that this device plays nowadays in the clinical settings, and what are the most medical applications used by the doctors. Table 3 shows that $100 \%$ of the physicians own Smartphones with almost equal percentages between the iPhone and the Android phones (52.8\% and 47.2\% respectively). The usability of medical related app among the doctors in Bahrain seems to be high, as shown in the table, where $94.3 \%$ of the participants use medical applications in their clinical practice. Among these medical apps, the most commonly used application with the highest usage percentage (34\%) was "Medscape" which is "the leading 
medical resource for physicians, medical students, nurses, and other healthcare professionals that offers fast and accurate clinical answers that help in decision making at the point-of-care" (Medscape.com, 2018). It gives meticulous information about diseases including its prevalence, diagnoses and the treatment options (drugs, procedures and follow-up) (ibid). The second most used application is "Uptodate" with a usage percentage among the respondents of $20.8 \%$. Uptodate is an application that can answer its subscribers' clinical questions anytime (UpToDate, 2018). It consists of a search tab that the physicians can write the keywords of any dilemma that they incur, and it gives them the answer directly and updated day by day (ibid). Then comes Omnio and BNF, and many other medical apps that were mentioned by the doctors beside the "other" choice of this question such as, Pedi-stat, instant anatomy, gestation age for pregnant women, Skyscape apps, etc. Most of the doctors of the sample use their medical applications during the working hours between 30 minutes $52.8 \%$ and an hour $30.2 \%$. Only $9.4 \%$ of the respondents do not use the medical apps they own. About the frequency of usage, the table shows that $28.3 \%$ of the participants use their applications 2 to 3 times a week, and $26.4 \%$ use them many times each day, while $3.8 \%$ do not use them and $13.2 \%$ use them infrequently, which suggests that the medical apps are being frequently used among physicians in Bahrain. Moreover, the usage percentages of the most prevalent types of medical applications are mentioned. As shown, the most used types of applications that seemingly have a distinctive role in the decision making among doctors were drug formulary apps $69.8 \%$ of respondents use them), then come disease diagnoses and management apps with a usage percentage of $62.3 \%$, then come medical calculators and journals access with percentages of usage of $56.6 \%$ and $47.2 \%$ respectively. Internet access and calendars are not widely used among doctors in Bahrain. Other types of medical applications that were mentioned by the doctors in the open-ended part of this question "others" were "research es", "iBooks" and "EHR" with low percentage of usage.

Table 3. Smartphone Usability

\begin{tabular}{|c|c|c|c|}
\hline & & Frequency & Valid \% \\
\hline \multirow[t]{2}{*}{ Have smart phone? } & Yes, i-Phone & 28 & $52.8 \%$ \\
\hline & Yes, android & 25 & $47.2 \%$ \\
\hline \multirow{2}{*}{$\begin{array}{l}\text { I use medical app on the smarl } \\
\text { phone. }\end{array}$} & No & 3 & $5.7 \%$ \\
\hline & Yes & 50 & $94.3 \%$ \\
\hline \multirow[t]{5}{*}{ What medical apps do you us } & Medscape & 8 & $34 \%$ \\
\hline & Omnio & 16 & $11.3 \%$ \\
\hline & Uptodate & 11 & $20.8 \%$ \\
\hline & BNF & 2 & $3.8 \%$ \\
\hline & Others & 16 & $30.2 \%$ \\
\hline \multirow{4}{*}{$\begin{array}{l}\text { What approximate time you } \\
\text { spend using these apps? }\end{array}$} & None & 5 & $9.4 \%$ \\
\hline & Up to $30 \mathrm{mins}$ & 28 & $52.8 \%$ \\
\hline & Up to 1 hour & 16 & $30.2 \%$ \\
\hline & More than 1 hour & 4 & $7.5 \%$ \\
\hline \multirow{6}{*}{$\begin{array}{l}\text { How frequently you use } \\
\text { medical apps? }\end{array}$} & I do not know them & 2 & $3.8 \%$ \\
\hline & Infrequently & 7 & $13.2 \%$ \\
\hline & Once a week & 5 & $9.4 \%$ \\
\hline & $2-3$ times per week & 15 & $28.3 \%$ \\
\hline & $1-2$ times per day & 10 & $18.9 \%$ \\
\hline & Many times, a day & 14 & $26.4 \%$ \\
\hline \multirow{2}{*}{$\begin{array}{l}\text { Forming drugs using the } \\
\text { medical apps }\end{array}$} & No & 16 & $30.2 \%$ \\
\hline & Yes & 37 & $69.8 \%$ \\
\hline \multirow{2}{*}{$\begin{array}{l}\text { Diagnosing diseases using the } \\
\text { medical apps }\end{array}$} & No & 20 & $37.7 \%$ \\
\hline & Yes & 33 & $62.3 \%$ \\
\hline \multirow{2}{*}{$\begin{array}{l}\text { Medical calendar using the } \\
\text { medical apps }\end{array}$} & No & 23 & $43.4 \%$ \\
\hline & Yes & 30 & $56.6 \%$ \\
\hline \multirow{2}{*}{ Access Journal/Database } & No & 28 & $52.8 \%$ \\
\hline & Yes & 25 & $47.2 \%$ \\
\hline \multirow{2}{*}{$\begin{array}{l}\text { Internet/E-mail access using } \\
\text { the medical apps }\end{array}$} & No & 29 & $54.7 \%$ \\
\hline & Yes & 24 & $45.3 \%$ \\
\hline \multirow{2}{*}{$\begin{array}{l}\text { Calendar access using the } \\
\text { medical apps }\end{array}$} & No & 38 & $71.7 \%$ \\
\hline & Yes & 15 & $28.3 \%$ \\
\hline \multirow[t]{2}{*}{ Others } & No & 48 & $90.6 \%$ \\
\hline & Yes & 5 & $9.4 \%$ \\
\hline
\end{tabular}




\subsection{EMR Acceptance}

A descriptive analysis was executed to know the percentages of agreement on each statement among the participants, in addition to regression analysis to test the linear relationship among the hypothesized variables. Table 4 shows the percentages of the usage of EMR in the clinical practice among participants. As resulted from the analysis, $62 \%$ of the respondents do use the EMR in their practice while $37.7 \%$ still do not use them.

Table 4. EMR in Practice

\begin{tabular}{llcc}
\hline & & Frequency & Valid Percent \\
\hline Do you use EMRs in your practice? & No & 20 & 37.7 \\
& Yes & 33 & 62.3 \\
& Total & 53 & 100 \\
\hline
\end{tabular}

\subsection{Regression Analysis and Hypotheses Testing}

\subsubsection{Usefulness of EMR and the Intention to use it Among Doctors}

Table 5 shows that the PU has a significant positive relationship to Intention to Use of EMR, with a Beta coefficient value of $(B=0.438)$ suggesting a strong relationship with a significance level of $<0.01$ which gives an evidence that the first hypothesis (H1) is correct and can be accepted.

Table 5. Regression for PU Effect on Acceptance of EMR

\begin{tabular}{|c|c|c|c|c|c|}
\hline \multicolumn{6}{|c|}{ Dependent Variable: Acceptance (Intention to Use EMRs) } \\
\hline \multicolumn{6}{|c|}{$\mathrm{F}=10.195(\mathrm{p}=0.003<0.01), \mathrm{R} 2=0.192$, adjusted $\mathrm{R} 2=0.173$} \\
\hline \multirow{3}{*}{$\begin{array}{l}\text { Model } \\
\qquad(\text { Constant })\end{array}$} & \multicolumn{2}{|c|}{ Unstandardized Coefficients } & Standardized Coefficients & \multirow[b]{2}{*}{$\mathrm{t}$} & \multirow[b]{2}{*}{ Sig. } \\
\hline & $\mathrm{B}$ & Std. Error & Beta & & \\
\hline & 1.803 & 0.597 & & 3.020 & 0.004 \\
\hline PU & 0.503 & 0.158 & 0.438 & 3.193 & 0.003 \\
\hline
\end{tabular}

\subsubsection{Ease of Use of EMR and the Intention to use it among Doctors}

Table 6 shows that the PEOU has a significant positive relationship to Intention to Use of EMR, with a Beta coefficient value of $(B=0.464)$ suggesting also strong relationship with a significance level of $<0.01$ which gives an evidence that the first hypothesis (H2) is correct and can be accepted.

Table 6. Regression for PEOU Effect on Acceptance of EMR

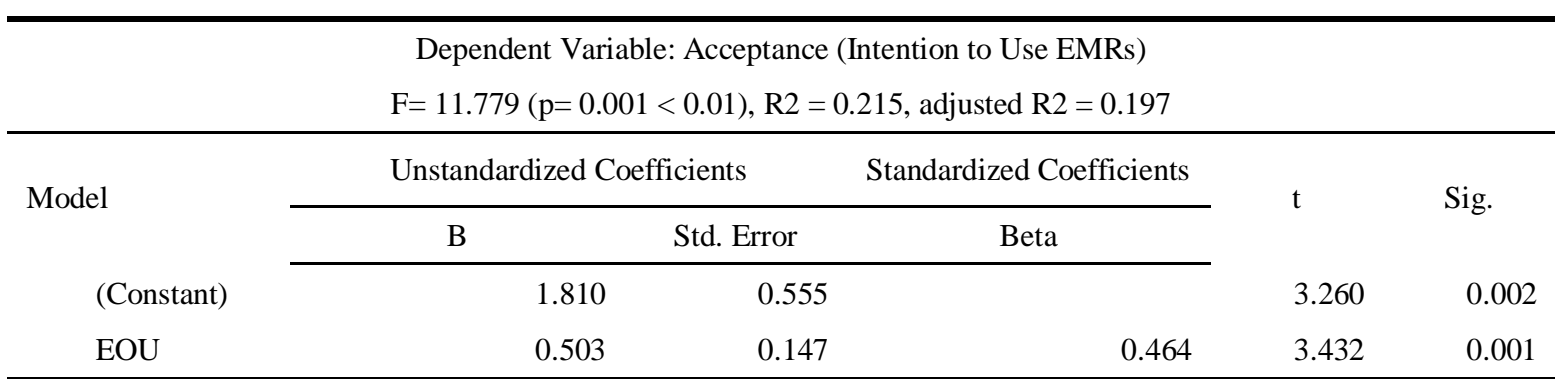

\subsubsection{Job Relevance and Quality of Output of EMR and the Usefulness of EMR}

Table 7 shows that the Job Relevance and Output Quality have significant positive relationships to PU of EMR, with Beta coefficients value of $(B=0.415$ and 0.478 respectively) suggesting strong relationship with significance levels of $<0.01$ which gives an evidence that the first hypothesis ( $\mathrm{H} 3$ and $\mathrm{H} 4$ respectively) are correct and can be accepted. 
Table 7. Regression for Job Relevance and Output Quality Effect on PU of EMR

\begin{tabular}{|c|c|c|c|c|c|}
\hline \multicolumn{6}{|c|}{ Dependent Variable: PU } \\
\hline \multicolumn{6}{|c|}{$\mathrm{F}=50.647(\mathrm{p}=0.000<0.01), \mathrm{R} 2=0.707$, adjusted $\mathrm{R} 2=0.693$} \\
\hline \multirow{2}{*}{ Model } & \multicolumn{2}{|c|}{ Unstandardized Coefficients } & Standardized Coefficients & \multirow[b]{2}{*}{$\mathrm{t}$} & \multirow[b]{2}{*}{ Sig. } \\
\hline & $\mathrm{B}$ & Std. Error & Beta & & \\
\hline (Constant) & 0.883 & 0.291 & & 3.035 & .004 \\
\hline RELEVENCE & 0.352 & 0.111 & 0.415 & 3.156 & .003 \\
\hline OUTPUT QUALITY & 0.424 & 0.116 & 0.478 & 3.640 & .001 \\
\hline
\end{tabular}

\section{CONCLUSION}

Bahrain is a developing and advanced country that is found to have extensive modernization utilization of the medical information over several years. The Kingdom has shown a tremendous growth in integrating the information technology in the functioning of the hospitals in the country which helps the healthcare professionals and patients to have quality healthcare with cost and time efficiency starting as early as 1993 with ALCARE system at the BDF hospital until now with many more improvements and internet based EMRs and Hospital Information Systems across all governmental hospitals. Also, it was quite clear that people have access to high tech gadgets in the Kingdom which increases their interface interaction with the technology and help them learn new techniques and technologies in a better manner. Therefore, effective strategies that are adopted in a systemic manner will help to achieve success and growth in the healthcare. Medical Informatics have found to have a positive effect on the work that provides faster and ease access to information and thus lets the healthcare professional make final decisions. Productivity, speed and efficiency at work is found to be increased which is like that of who claims that EMR helps to perform people in a better way that is helpful for the patients which lets the researcher accepts the four hypotheses. The hypotheses used in the research helped to reach the objective of the study which is to determine the acceptance and usability of the end-users for the EMR and mobile Medical Apps. It was found that people have hesitations for implementation of a new system which is in accordance to (Illiger et al., 2014) is a major factor of accepting a system. Any new change, nevertheless, has different resistances from people as they don't like to change their normal and well-settled routines but effective leadership, training and understanding of the system can help people own a change and let them implement it in a successful manner and this apply on physicians. Thus, it is important for organizations to understand the core concepts of the change management while implementing EMRs in the hospital and effectively use these techniques to let people own the change. In Hospital organizations as patients are at the centric core of the model thus both internal and external stakeholders should be taken into confidence while implementing the new systems which is installed in a way that change process can be smooth. The analysis regarding the usability of Smartphones in the clinical practice by the doctors in Bahrain showed that the doctors in Bahrain have medical related apps on their own Smartphones and they tend to use these applications frequently in their medical practice to help them take decisions at the point of care and ease up the process of diagnoses. Different apps with different functions are downloaded on their phones and used daily. On the other hand, regarding the Acceptance of EMRs, it was concluded from this study that the perceived ease of use and perceived usefulness of EMRs play an important role in determining the intention of the doctors in Bahrain to use and adopt such system in their clinical practice and this lead to the acceptance of $\mathrm{H} 1$ and $\mathrm{H} 2$ in this research, agreeing with the previous studies that were done in regards of the EMRs among physicians in many other countries and mentioned earlier in the research background. Moreover, the job relevance and the quality of output of the system also proved to have a significance relationship with the Perceived Usefulness (PU) affecting the intention to use the EMR indirectly, and this also agree with the previous literature. 


\section{REFERENCES}

Chang, C. P. (2015) The Technology Acceptance Model and Its Application in a Telehealth Program for the Elderly with Chronic Illnesses. Hu Li Za Zhi, 62(3), 11.

Davis, F. D., Bagozzi, R. P., \& Warshaw, P. R. (1989), User Acceptance of computer technology: A comparison of two theoretical models. Management Science, 35, 982-1003, doi:10.1287/mnsc.35.8.982

Gagnon, M. P., Ghandour, E. K., Talla, P. K., Simonyan, D., Godin, G., Labrecque, M., Ouimet, M., \& Rousseau, M. (2014). Electronic health record acceptance by physicians: testing an integrated theoretical model. Journal of biomedical informatics, 48, 17-27.

Gan, S. K. E., Koshy, C., Nguyen, P. V. \& Haw, Y. X. (2016) An overview of clinically and healthcare related apps in Google and Apple app stores: connecting patients, drugs, and clinicians. Scientific phone apps and mobile devices, 2(1), 8 .

Hamidfar, M., Limayem, M., \& Zegordi, S. H. (2008) Using the UTAUT model to explore Iranian physicians and nurses' intention to adopt electronic patient record. Proceedings of the International Conference on E-Learning, E-Business, Enterprise Information Systems, and E-Government, Las Vegas, Nevada, USA.

Illiger, K., Hupka, M., von Jan, U., Wichelhaus, D., \& Albrecht, U. V. (2014) Mobile Technologies: Expectancy, Usage, and Acceptance of Clinical Staff and Patients at a University Medical Center. JMIR mHealth and uHealth, 2(4).

Ketikidis, P., Dimitrovski, T., Lazuras, L., \& Bath, P. A. (2012). Acceptance of health information technology in health professionals: an application of the revised technology Acceptance model. Health informatics journal, 18(2), 124-134.

Lakbala, P., \& Dindarloo, K. (2014) Physicians' perception and attitude toward electronic medical record. SpringerPlus, $3(1), 63$.

Marques, A., Oliveira, T., \& Martins, M. O. (2011). Medical Records System Adoption in European Hospitals. The Electronic Journal Information Systems Evaluation, 14(1), 89-99.

Medscape.com. (2018). Medscape App. [online] Available at: https://www.medscape.com/public/medscapeapp [Accessed 8 May 2018].

Moeinedin, F. (2011) Assessing Primary Care Physicians' Attitudes Towards Adoption of an Electronic Tool to Support Cancer Diagnosis. MS. University of Toronto.

Okazaki S., Blas S. S., \& Castañeda J. A. (2015). Physician Adoption of Mobile Health Monitoring Systems in Spain: Competing Models and Impact of Prior Experience. Journal of Electronic Commerce Research, 16(3), 194.

Pai, F. Y., \& Huang, K. I. (2011) Applying the Technology Acceptance Model to the introduction of healthcare information systems. Technological Forecasting and Social Change, 78(4), 650-660.

Patel, R. K., Sayers, A. E., Patrick, N. L., Hughes, K., Armitage, J., \& Hunter, I. A. A (2015) UK perspective on smartphone use amongst doctors within the surgical profession. Annuals of Medicine and Surgery, 4(2), 107-112.

Payne K. F. B., Wharrad, H., \& Watts, K. (2012) Smartphone and medical related App use among medical students and junior doctors in the United Kingdom (UK): a regional survey. BMC medical informatics and decision making, 12(1), 121.

Saunders, M., Lewis, P. \& Thornhill, A. (2012) Research Methods for Business Students. (6th Ed.). England: Pearson.

Sclafani, J., Tirrell, T. F., \& Franko, O. I. (2013) Mobile tablet use among academic physicians and trainees. Journal of medical systems, 37(1), 1-6.

Sezgin, E., \& Özkan, S. (2014) Assessment of Information Technology Use in Small and Medium-Sized Enterprises: Empirical Investigation in Five Cases. In Information Systems for Small and Medium-sized Enterprises. Springer Berlin Heidelberg. 97-121

Sweis, R., Isa, A., Azzeh, H., Shtyh, B., Musa, E., \& AlBtoush, R. (2014) Nurses' resistance to the adoption of information technology in Jordanian hospitals. Life Science Journal, 11(4s), 8-18.

UpToDate. (2018). UpToDate Individual Subscriptions for Medical Professionals. [online] Available at: https://www.uptodate.com/home/uptodate-subscription-options-clinicians [Accessed 8 May 2018].

Venkatesh V., \& Davis F. D. A (2000) Theoretical extension of the technology acceptance model: Four longitudinal field studies. Management science, 46(2), 186-204.

Wyatt G., Sikorskii A., \& Wills C. E. (2013). Development and Initial Validation of a Complementary and Alternative Medicine (CAM) Knowledge Instrument. Journal of nursing measurement 21(1), 55-63.

Wyatt J., \& Liu J. (2002). Basic concepts in medical informatics. Journal of Epidemiology \& Community Health; 56, 808-812. doi 10.1136/jech.56.11.808 